\title{
Инновационная технология приготовления субстрата в стерильных условиях для культивирования вешенки
}

\section{Н.Л. Девочкина, Р.Дж. Нурметов, Л.Н. Прянишникова, С.В. Мукиенко}

Описаны особенности полного технологического процесса приготовления композиционного субстрата для выращивания вешенки на основе соломы и лузги семян подсолнечника в сочетании с содержащими азот питательными добавками в ООО «Апрель» (Тула), а также результаты внедрения в производство новейшего способа термической обработки субстрата методом стерилизации в автоклаве, позволяющего получать высококачественный субстрат, свободный от патогенов и вредителей.

Ключевые слова: субстрат, технология, термическая обработка, автоклавирование, солома, лузга, добавки, вешенка, плодовые тела, культивационные сооружения.

$\mathrm{B}$ ешенка занимает одно из ведущих мест по объему мирового производства культивируемых съедобных грибов, уступая первенство лишь шампиньону двуспоровому, будучи второй по значимости промышленной грибной культурой. Мировое производство вешенки составляет 1,5 млн т в год. Выращиванием вешенки в промышленных масштабах занимаются в Италии, Франции, Бельгии, Нидерландах, Японии, Тайвани, Китае. Страны Юго-Восточной Азии: Китай, Тайвань, Южная Корея, Индонезия, Филиппины, Индия в отличие от европейских стран, США и Канады, отдают предпочтение выращиванию именно ксилотрофных грибов (т.е. разрушающих древесину или произрастающих на целлюлозосодержащих материалах): шиитаке, зимнему грибу, опенку летнему, опенку мраморному и т.д.

До середины семидесятых годов XX века основным способом выращивания дереворазрушающих грибов, в том числе вешенки был экстенсивный способ выращивания, который заключался в том, что мицелием гриба заражали отрубки древесины, мицелий развивался медленно, а плодоношение происходило в течение 2-3 и более лет. Плантации находились в естественных условиях произрастания, и урожай плодовых тел полностью зависел от климатических факторов. Такие результаты не устраивали производителей, поскольку урожайность и эффективность подобного производства была чрезвычайно низкой. Восьмидесятые годы XX века ознаменовались бурным развитием промышленного грибоводства в Европе, началом внедрения интенсивных способов культивирования съедобных грибов: шампиньона, вешенки, шиитаке [1].

Интересен опыт производства съедобных грибов в Венгрии, в кооперативе «Дуна». Микологические исследования в Венгрии имеют многолетние традиции. Уже в концеXIX века в Венгрии выращивали шампиньоны в пещерах, оставшихся после выработки известняка. В 1926 году в лаборатории впервые начали выращивать стерильный мицелий шампиньона. В пятидесятых годах XX века была организована Специализированная лаборатория по культивированию съедобных грибов.

С этого же периода началась активная разработка технологий культивирования вешенки. Первоначально это была экстенсивная природная технология выращивания грибов на древесных отрубках. Использовали местные дикорастущие штаммы вешенки. Технология получила распространение в Венгрии, Германии, Италии, Австрии. В середине шестидесятых годов была разработана стерильная технология выращивания вешенки на различных растительных лигниноцеллюлозных субстратах. Субстрат обрабатывали паром в автоклавах при повышенном давлении и температуре более $120{ }^{\circ} \mathrm{C}$. Стерильный способ был первым промышленным способом выращивания вешенки обыкновенной и был запатентован в 1966 году [2].

Дальнейшее развитие технологии шло по упрощенной схеме и заключалось в замене автоклавирования обработкой субстрата паром при атмосферном давлении и температуре $100{ }^{\circ} \mathrm{C}$. Этот вариант оказался существенно проще и дешевле, на практике он обеспечивал достаточно большой выход готового чистого от инфекционных начал субстрата. В этот же период в Венгрии были начаты работы по приготовлению субстрата в массе в тоннелях. Тоннели пастеризации, как специализированные сооружения, вмещали большой объем субстрата, что позволило создать крупные централизованные производства, которые поставляли готовый к плодоношению субстрат фермерам. Максимальные объемы производства вешенки в Венгрии до 2 тыс. Т в год были в первый половине девяностых годов XX века. Продукцию - плодовые тела вешенки -экспортировали в Австрию и Германию.

Сегодня в Российской Федерации вешенка как продукт питания становится очень популярной благодаря своим вкусовым качествам. Ежегодный объем ее производства в РФ составляет немногим более 4 тыс. т. По мнению многих специалистов, перспективы роста производства вешенки в нашей стране чрезвычайно велики, поскольку объективно существуют все условия для его расширения. 
Пример стабильного круглогодичного интенсивного производства плодовых тел вешенки - предприятие ООО «Апрель» [3].

Интенсивный способ выращивания вешенки обыкновенной существенно отличается от экстенсивного как используемыми видами субстратов (активно используются отходы с. - х. производства), так и сокращенной продолжительностью периода выращивания до получения урожая плодовых тел (от 30 сут.). Процесс интенсивного выращивания грибов стал полностью управляемым и осуществляется в специализированных культивационных сооружениях с регулируемым микроклиматом. Плодовые тела гриба собирают непрерывно в течение круглого года. Число оборотов культуры при полном технологическом цикле производства выросло с 4-5 до 8-10 [4].

Сегодня активно развиваются несколько направлений интенсивного выращивания вешенки, в том числе и стерильная технология приготовления субстрата, о который мы хотим рассказать в этом материале. Об уникальном промышленном производстве вешенки и шиитаке в Туле, на базе которого специалисты ВНИИ овощеводства - филиала ФГБНУ Федерального научного центра овощеводства ведут исследования по разработке и обоснованию элементов технологии приготовления субстрата для культивирования вешенки в стерильных условиях.

Производственный комплекс ООО «Апрель» выращивает грибы на основе полного технологического цикла (рис. 1). Система производства многозональная, что подразумевает разбивку полного технологического цикла на несколько технологических зон (отделений), в которых происходят процессы приготовления субстрата; его термической обработки в специализированном автоклаве; посева мицелия в субстрат в стерильных условиях (боксе) и проращивания мицелия в субстрате в емкостях в технологической зоне инкубации; культивирование и сбор урожая плодовых тел гриба в культивационных камерах с размещением емкостей для выращивания на многоярусных стеллажах.

Субстрат готовят на основе композиции соломы озимой пшеницы и лузги семян подсолнечника с применением минеральных и органических добавок. Приготовление

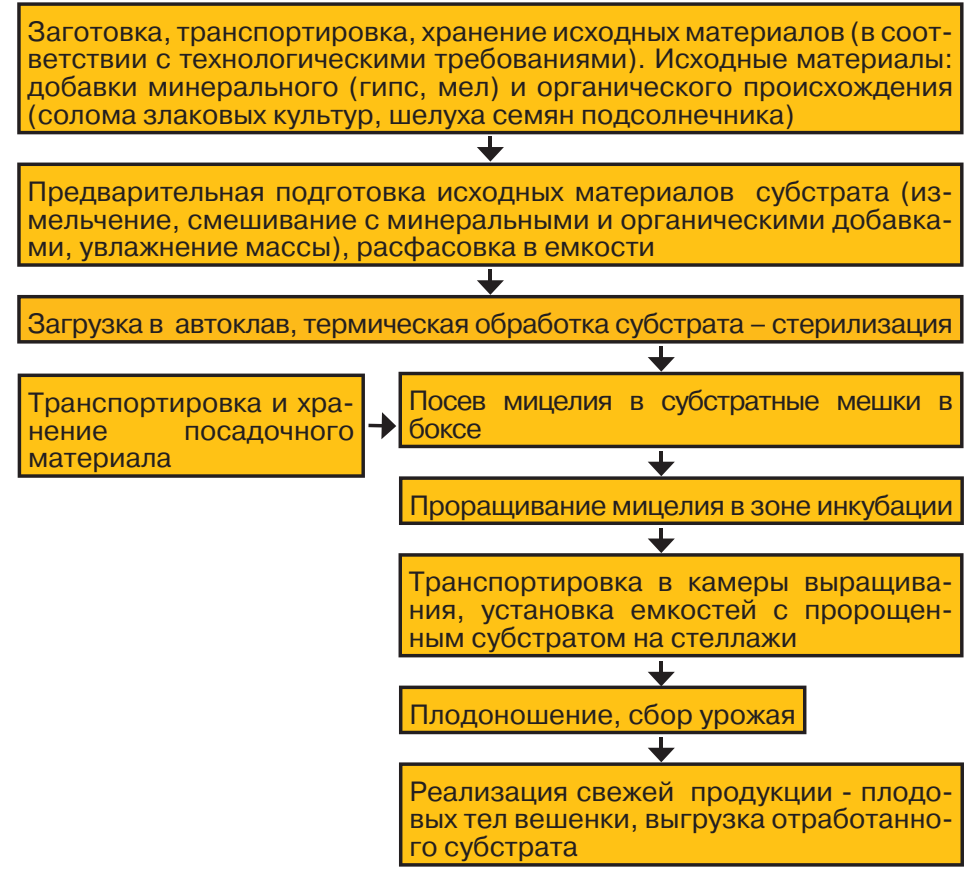

Рис. 1. Схема полного технологического цикла культивирования вешенки (многозональная система), стеллажная стационарная культура.

субстрата обслуживает специализированный комплекс машин и механизмов (рис. 2). Массу стерилизуют в автоклаве (паровом стерилизаторе) при температуре $121{ }^{\circ} \mathrm{C}$ в течение трех часов. Равномерное распределение пара в объеме автоклава обеспечивает 100\%-ный выход стерильных субстратных блоков, которые в пластиковых ящиках на стеллажах выгружаются и пере-

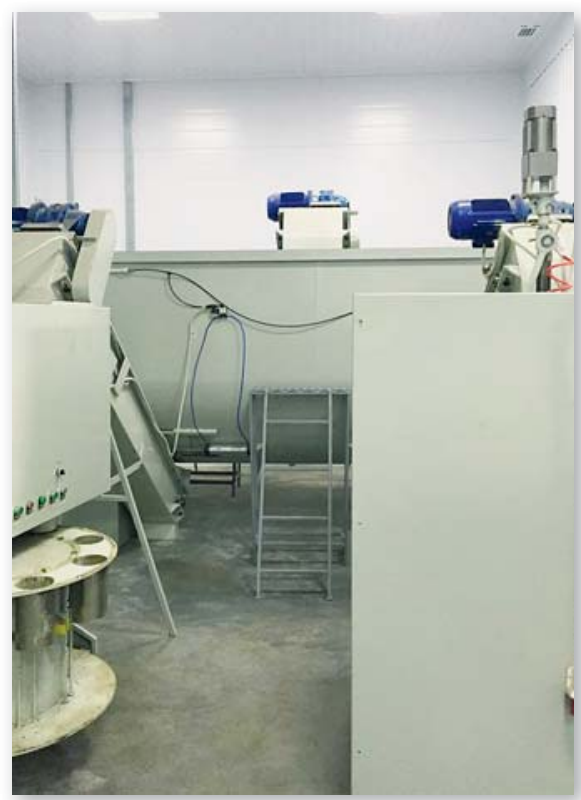

Рис. 2. Специализированный комплекс машин и механизмов для приготовления субстрата мещаются после автоклавирования в помещение для охлаждения в стерильной зоне (в предбокснике). Масса загрузки автоклава 5,3-5,5 т (рис. 3). Мицелий вешенки в емкостях проращивают также в специальной зоне инкубации, где поддерживают оптимальный температурно-влажностный режим (рис. 4). Плодовые тела вешенки выращивают в пластиковых емкостях с мас-

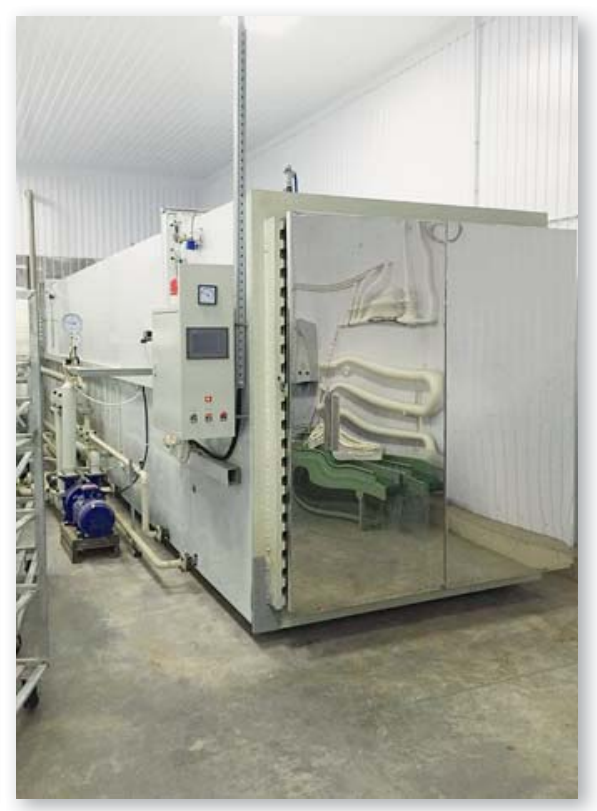

Рис. 3. Автоклав 


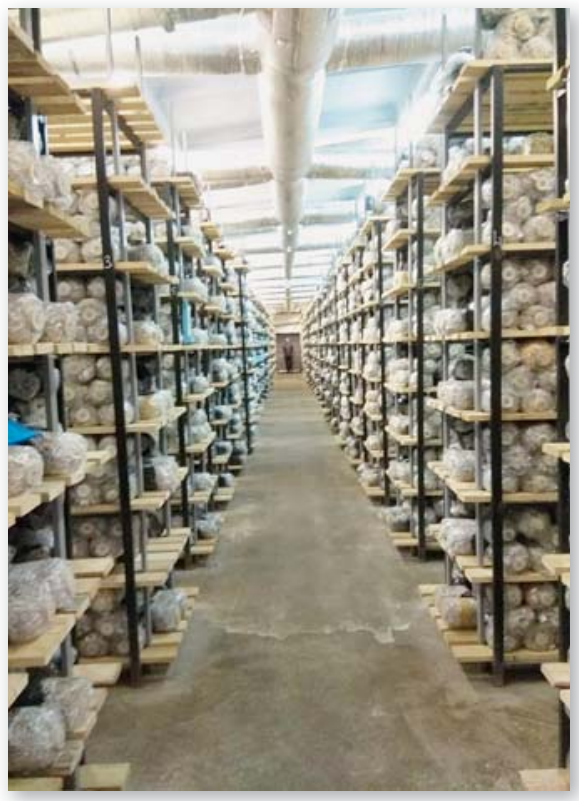

Рис. 4. Зона инкубации

сой субстрата 1,2-1,3 кг на многоярусных стеллажах в камерах выращивания. Сбор урожая - один раз в первую волну плодоношения (рис. 5).

Для большинства производителей вешенки организация полного технологического цикла производства субстрата - достаточно сложная проблема. Качество субстрата, который используют для выращивания плодовых тел гриба, имеет решающее значение, так как на $80 \%$ определяет урожайность плодовых тел вешенки, и тем самым экономическую эффективность получаемого урожая.

Сравнивая более простые способы термической обработки исходных материалов: замачивание в горячей воде, ксеротермическую обработку, обработку паром в масcе со стерилизацией субстрата в автоклаве, необходимо отметить, что стерилизация является самым жестким методом обработки субстрата. Благодаря ей уничтожаются все виды микроорганизмов, в том числе даже спорообразующие бактерии. Микроорганизмы - прямые конкуренты мицелию вешенки по отношению к питательному субстрату. После стерилизации субстрата в автоклаве при должном контроле температурного режима и при повышенном атмосферном давлении 1,1-1,2 атм обеспечивается практически 100\%-ный выход чистого стерильного субстрата. Это позволяет активно развиваться ми-

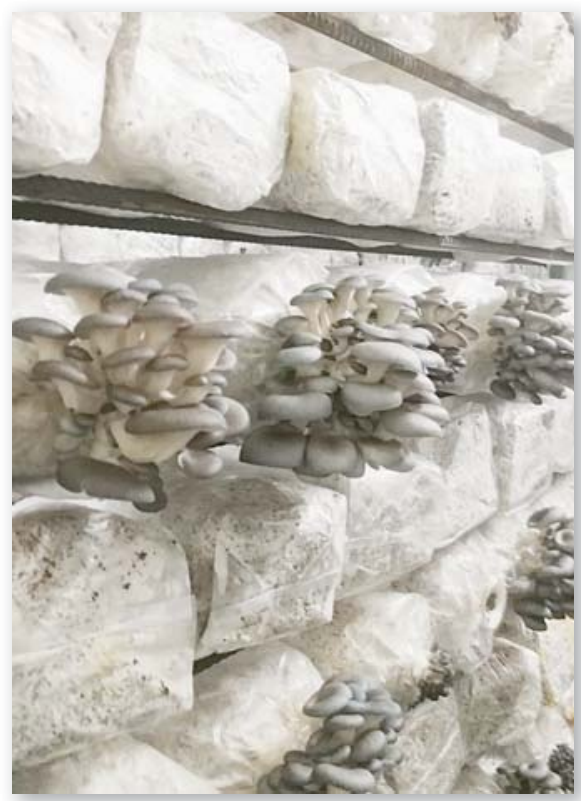

Рис. 5. Плодовые тела вешенки в камере выращивания

целию вешенки в наиболее благоприятных условиях при оптимальном температурном режиме в камере инкубации. В технологиях, использующих другие методы термической обработки субстрата, трудно достичь высокой стерильности среды, поскольку могут быть спровоцированы условия, при которых субстрат может быть повторно заражен конкурирующими с мицелием вешенки микроорганизмами, плесеням, среди которых преобладает черная плесень микогон, зеленая - триходерма. Зачастую зараженность субстрата достигает 30\% и более. Считается, что стерильная технология достаточно затратна, но зато она может позволить достичь высоких показателей содержания азота в массе субстрата (2-4\%), и получить урожай до 40-50\% от массы субстрата $[5,6]$. Во всем мире стерильная технология - основная технология, применяемая для выращивания посадочного материала съедобных грибов.

\section{Библиографический список}

1.Сычев П.А., Ткаченко Н.П. Грибы и грибоводство. М. ООО «Издательство АСТ», Донецк «Сталкер», 2013. 511 с.

2.Дудка И.А. Промышленное культивирование съедобных грибов. Киев: Наукова Думка, 1978. 264 с.

3.Девочкина Н.Л., Нурметов Р.Дж., Мещерякова Р.А., Прянишникова Л.Н. Оптимизация состава субстрата для промышленного культивирования вешенки // Картофель и овощи. 2018. № 9. С. $19-21$.

4.Девочкина Н.Л., Нурметов Р.Д. Выращивание шампиньона и вешенки. Руководство. М. Россельхозакадемия, 2010. 67 с.
5.Тишенков А.Д. Субстраты для культивирования вешенки. Ч. 2. Приготовление субстратов. М.: Школа грибоводства. 1999. 57 с

6.Девочкина Н.Л., Дугуниева Л.Г.. Иванова М.И., Нурметов Р.Д. Инвестиционная привлекательность промышленного грибоводства// Экономика сельского хозяйства России. 2018. №11. С.52-59.

\section{Об авторах}

\section{Девочкина Наталия Леонидовна,}

доктор с. - х. наук, г.н.с. отде-

ла защищенного грунта и грибоводства, ВНИИО-филиал ФГБНУ

«Федеральный научный центр овощеводства». E-mail: vniioh@yandex.ru Нурметов Рафик Джамович, доктор с. - х. наук, профессор, г.н.с. отдела защищенного грунта и грибоводства, ВНИИО-филиал ФГБНУ «Федеральный научный центр овощеводства».E-mail: vniioh@yandex.ru

\section{Прянишникова Людмила}

николаевна, канд. техн. наук,

в.н.с. отдела защищенного грунта и грибоводства, ВНИИО-филиал ФГБНУ «Федеральный научный центр овощеводства».

\section{E-mail:vniioh@yandex.ru}

\section{Мукиенко Сергей Викторович, тех-} нолог ООО «Апрель» (Тула).

E-mail: tudvorik@mail.ru

Innovative technology of preparation of the substrate in sterile conditions for the cultivation of oyster mushrooms

N.L. Devochkina, DSC, chief research fellow of the department for greenhouse end mushroom industry, ARRIVG-branch of FSBSI Federal Scientific Vegetable Center. E-mail:vniioh@yandex.ru

R.D. Nurmetov, DSc, chief research fellow, professor of the department for greenhouse end mushroom industry, ARRIVG-branch of FSBSI Federal Scientific Vegetable Center. E-mail:vniioh@yandex.ru

L.N. Pryanishnikova, PhD, leading

research fellow department for greenhouse end mushroom industry, ARRIVG-branch of FSBSI Federal Scientific Vegetable Center. E-mail:vniioh@yandex.ru

S.V. Mukienko, technologist, LLC Aprel (Tula).E-mail: tuvorik@mail.ru

Summary. The features of the complete technological process of composite substrate preparation based on straw and husk of sunflower seeds in combination with nitrogen-containing nutritional additives at LLC Aprel (Tula) are described, as well as the results of the introduction into production of the latest method of heat treatment of the substrate by sterilization in an autoclave, which allows to obtain a high-quality substrate free of infectious agents and pests.

Keywords: substrate, technology, heat treatment, autoclaving, straw, husk, supplements, oyster mushroom, fruiting bodies, cultivation facilities. 